\section{Fruit Quality Indices in Eight Nance [Byrsonima crassifolia (L.) H.B.K.] Selections}

\author{
Raúl Medina-Torres ${ }^{1}$ \\ Universidad Autónoma de Nayarit, Facultad de Agricultura, Apdo. Postal 49, \\ Xalisco, NAY 63780, México
}

Samuel Salazar-García ${ }^{2}$

INIFAP-Campo Experimental Santiago Ixcuintla, Apdo. Postal 100, Santiago

Ixcuintla, NAY 63300, México

José Roberto Gómez-Aguilar ${ }^{3}$

Universidad Autónoma de Nayarit, Facultad de Agricultura, Apdo. Postal 49, Xalisco, NAY 63780, México

Additional index words. Malpighia crassifolia, nanche, golden spoon, murici, canonical discriminant analysis

\begin{abstract}
Nance [Byrsonima crassifolia (L.) HBK.] is a tropical fruit cultivated along the coastal areas of Mexico. Nance consumption has increased due to its versatility, as it can be used as fresh fruit, refreshments, and alcoholic beverages and also for preparing fruit rolls, bottled drinks, jellies, syrup, ice cream, and cakes. However, the broad variation in fruit quality parameters, like juice acidity, total soluble solids, skin color, and size, seems to limit its use. Since fruit quality can be influenced by the parameter used, multivariate canonical discriminant analysis (CDA) was used to discriminate among nance selections. The objective of this study was to find the best quality indices using physical and chemical fruit characteristics from eight nance selections cultivated in the state of Nayarit, Mexico. Six physical and five chemical variables of fruit quality were studied to determine the relative contribution of each variable to the discrimination between nance selections. Two canonical discriminant functions $\left(\mathrm{CDF}_{1}\right.$ and $\left.\mathrm{CDF}_{2}\right)$ explained $>80 \%$ of the accumulated variation among nance selections. The total soluble solids (TSS) to titratable acidity (TA) ratio was dominant on the $\mathrm{CDF}_{1}$ (standardized canonical coefficient $=\mathbf{2 . 4 6}$ ), therefore, this ratio could be used as the best quality index to select nance fruit. The following TSS to TA values are proposed to classify the nance selections studied: a) 5.1 to 8 as sour fruit (Sour-small and Purple selections), b) 8.1 to 10 as sweet-sour fruit (Conical, Improved, Sweet-sour-1, Sweet-sour-2, and Sweet-sour-3 selections), and c) $>10$ as sweet fruit (Sangunga selection).
\end{abstract}

Little research has been done in Mexico on nance (Byrsonima crassifolia). Besides cultivation of the criollo types, which usually are backyard or mountain trees, there is a moderate range of selections commercially grown in states along the Pacific coast and Gulf of Mexico (Pennington and Sarukhan, 1968). In the state of Nayarit (on the Pacific coast), there are 207 ha of commercial nance orchards that produce a crop worth more than $\$ 0.5 \times 10^{6}$ per year. The cultivated area is increasing since many rural families benefit from harvesting this crop during the rainy season (July to October). The main production areas in Nayarit are located along the coast, in counties with savanna type vegetation, like Acaponeta, Santiago Ixcuintla, Compostela, Rosamorada, Ruiz, and San Blas.

Nance fruit are round drupes produced on 10- to 15-cm-long inflorescences. At maturity

Received for publication 15 Nov. 2002. Accepted for publication 22 Sept. 2003.

${ }^{1}$ Department of Fruit Crops.

${ }^{2}$ Plant physiologist and corresponding author; e-mail samuelsalazar@prodigy.net.mx.

${ }^{3}$ Department of Statistics. they are 17 to $20 \mathrm{~mm}$ in transverse diameter with slightly orange to yellow skin, and sweet and sour pulp surrounding a hard stone (seed), which has one to three white embryos covered by a thin seed coat (Pennington and Sarukhan, 1968). A nance harvest index has not been yet established.A local common practice is to pick up the fruit from the ground as fruit picked from the tree do not reach edible quality. In Nayarit, the peak collection from the ground occurs from July throughout September, although there are orchards that may have a light but constant yield all through the year.

Nance fruit is nutritious and complements the local inhabitants' diet. The fruit have a high content of vitamins A and C-up to 369 $\mathrm{mg} / 100 \mathrm{~g}$ and $650 \mathrm{mg} \cdot \mathrm{g}^{-1}$, respectively (Nava and Uscanga, 1978). Nance is consumed as a fresh fruit for its exquisite sweet-and-sour taste. It is also used as a component of refreshments, ice cream, salads, and in the preparation of alcoholic beverages. Nance has great potential for preparing fruit rolls, bottled drinks, jellies, syrup, cakes, and many other products. However, the broad variation in fruit quality parameters like sourness, $\mathrm{pH}$, total soluble solids, and reducing sugars seems to limit a wider use.
Defining fruit quality standards is not an easy task as external fruit characteristics like skin color and size are not always good indicators of the internal composition. As fruit approach maturity, many physical and chemical changes take place. Usually, titratable acidity, firmness, and starch decline while total sugars increase (Mann and Singh, 1985).

Since fruit quality can be influenced by the parameter being evaluated, the use of multivariate analysis, like canonical discriminant analysis (CDA), may be a useful statistical tool to identify differences between groups of individuals (or treatments) and improve the understanding of the relationships between the variables measured within those groups (Cruz-Castillo et al., 1994). CDA finds linear functions of quantitative variables that maximize the separation of two or more groups of individuals formed a priori while keeping variation within the groups, as small as possible. This approximation distinguishes several, not interrelated, canonical discriminant functions (CDFs) or canonical variables. These are linear combinations of the original variables that better separate the means from the groups from observations related to the variation within the groups (Rencher, 1992).

CDA maximizes the variation between the groups of individuals while minimizes the variation within the groups of the original variables. CDA summarizes in one or two CDFs the information contained in the different independent variables. The coefficients of the $\mathrm{CDF}$ are the canonical discriminant weights that are determined by the structure of the variance of the original variables through the groups of the dependent variable. The variables with high discriminant power generally present high weights and conversely (Kshirsagar, 1972). The first CDF, called $\mathrm{CDF}_{1}$, produces the maximum variation possible among the groups with regard to the variation within the groups, showing some differences between them to the highest degree possible. The $\mathrm{CDF}_{2}$ reflects differences between the groups not explained by $\mathrm{CDF}_{1}$, with a no correlation condition between $\mathrm{CDF}_{1}$ and $\mathrm{CDF}_{2}$. Similarly, $\mathrm{CDF}_{3}$ will not be correlated with $\mathrm{CDF}_{1}$ and $\mathrm{CDF}_{2}$ and so on (Cruz-Castillo et al., 1994). The objective of this study was to find the best quality indices using physical and chemical fruit characteristics from eight nance selections cultivated in the state of Nayarit, Mexico, by using CDA.

\section{Materials and Methods}

Fruit of the nance selections studied were obtained from 12-year-old trees grown from seed on commercial orchards in two production areas in the state of Nayarit: Los Medina, in Rosamorada County (N $21^{\circ} 57^{\prime}$; W $105^{\circ} 17^{\prime}$ $\left.16^{\prime}\right)$ and Mecatán (N 21 ${ }^{\circ} 33^{\prime}$; W $105^{\circ} 18^{\prime}$ ) in San Blas County. With the help of nance buyers and sellers, four nance selections were identified in each location. Their local names were used to identify the selections and were characterized a priori, according to consumer preferences (Table 1). Fruit of the selections Sangunga, Conical, Sour-small, and Purple 

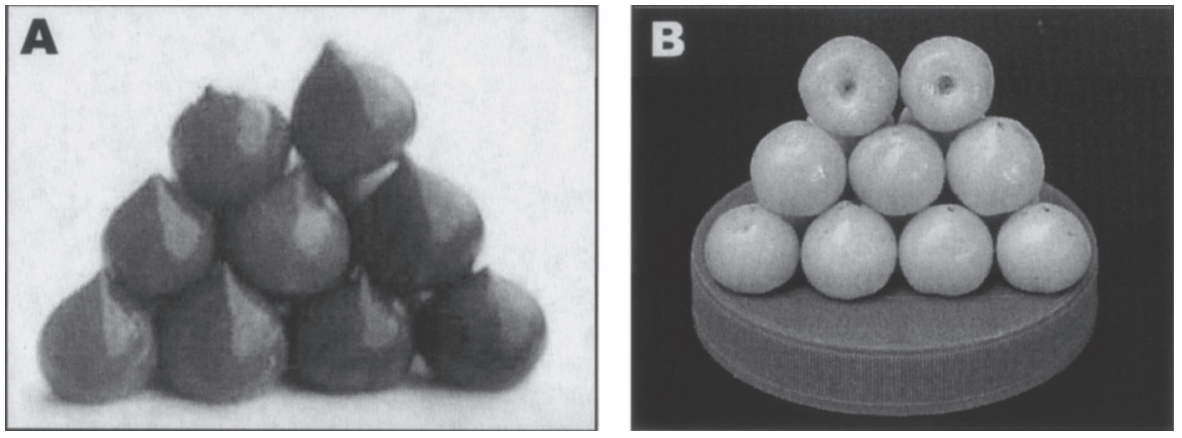

Fig. 1. Purple nance (top) and improved nance (bottom). Most commercial nance selections in Nayarit have yellow skin.

were obtained in Los Medina. In Mecatán, the selections tested were Improved, Sweet-sour-1, Sweet-sour-2, and Sweet-sour-3.

For each selection, fruit were obtained from one single tree on 7 Oct. 1999 once they had reached commercial maturity, which for nance is distinguished by the natural abscission of fruit, which is picked up from the ground. Ground underneath each tree canopy was cleared of fruit the day before fruit collection. Fruit physical and chemical characteristics were determined on a sample of 15 fruit per selection within $24 \mathrm{~h}$ after collection.
Total fresh fruit (FW) and seed fresh weight (SW) were determined using an electronic precision scale. Fruit length (L) and width (W) were measured with an electronic vernier caliper (Digimatic; Mitutoyo Co., Japan). The juice of 15 fruit from each selection was analyzed for total soluble solids (TSS) with a hand refractometer(Atago Co., LTD, Japan), juice pH with a digital potentiometer ( $\mathrm{pH}$ meter 320; Corning, U.K.), and titratable acidity (TA) in terms of citric acid $(\mathrm{g} / 100 \mathrm{~g}$ fresh weight) by titration using the procedure described by Herrero and Guardia (1992). The TSS to TA and TSS to $\mathrm{pH}$

Table 1. Characteristics of the nance selections evaluated.

\begin{tabular}{|c|c|c|c|c|c|}
\hline Selection & Location & $\begin{array}{l}\text { Fruit } \\
\text { skin } \\
\text { color }\end{array}$ & $\begin{array}{l}\text { Fruit } \\
\text { size }\end{array}$ & $\begin{array}{l}\text { Fruit } \\
\text { shape }\end{array}$ & $\begin{array}{l}\text { Pulp } \\
\text { taste }\end{array}$ \\
\hline Sangunga & Los Medina & Yellow & Large & Elliptical & Sweet \\
\hline Conical & Los Medina & Yellow & Medium & Conical & Very acid \\
\hline Sour-small & Los Medina & Yellow & Very small & Rounded & Acid \\
\hline Purple & Los Medina & Purple & Small & Rounded & Sweet \\
\hline Improved & Mecatán & Yellow & Large & Rounded & Sweet-sour \\
\hline Sweet-sour-1 & Mecatán & Yellow & Medium & Elongated & Sweet-sour \\
\hline Sweet-sour-2 & Mecatán & Yellow & Medium & Elongated & Sweet-sour \\
\hline Sweet-sour-3 & Mecatán & Yellow & Medium & Rounded & Sweet-sour \\
\hline
\end{tabular}

Table 2. Fruit physical characteristics of nance selections.

\begin{tabular}{|c|c|c|c|c|c|c|}
\hline Selection & $\begin{array}{c}\text { Fruit } \\
\text { length } \\
(\mathrm{L}) \\
(\mathrm{mm})\end{array}$ & $\begin{array}{c}\text { Fruit } \\
\text { width } \\
(\mathrm{W}) \\
(\mathrm{mm})\end{array}$ & $\mathrm{L}: \mathrm{W}$ & $\begin{array}{c}\text { Fruit fresh } \\
\text { wt (FW) } \\
\text { (g) }\end{array}$ & $\begin{array}{c}\text { Seed fresh } \\
\text { wt (SW) } \\
(\mathrm{g})\end{array}$ & FW:SW \\
\hline$\overline{\text { Sangunga }}$ & $18.2 \mathrm{c}^{\mathrm{z}}$ & $21.5 \mathrm{~b}$ & $0.84 \mathrm{e}$ & $5.55 \mathrm{~b}$ & $0.38 \mathrm{a}$ & $14.7: 1 \mathrm{de}$ \\
\hline Conical & $18.1 \mathrm{c}$ & $19.3 \mathrm{c}$ & $0.94 \mathrm{bcd}$ & $4.15 \mathrm{c}$ & $0.13 \mathrm{e}$ & $30.5: 1 \mathrm{a}$ \\
\hline Sour-small & $13.8 \mathrm{e}$ & $15.5 \mathrm{e}$ & $0.90 \mathrm{~d}$ & $2.14 \mathrm{~d}$ & $0.30 \mathrm{bc}$ & $7.2: 1 \mathrm{f}$ \\
\hline Purple & $16.2 \mathrm{~d}$ & $16.8 \mathrm{~d}$ & $0.96 \mathrm{abc}$ & $2.84 \mathrm{c}$ & $0.23 \mathrm{~d}$ & $12.9: 1 \mathrm{e}$ \\
\hline Improved & $22.9 \mathrm{a}$ & $24.8 \mathrm{a}$ & $0.92 \mathrm{~cd}$ & $8.87 \mathrm{a}$ & $0.40 \mathrm{a}$ & $22.4: 1 \mathrm{~b}$ \\
\hline Sweet-sour-1 & $20.4 \mathrm{~b}$ & $20.9 \mathrm{~b}$ & $0.98 \mathrm{ab}$ & $5.46 \mathrm{~b}$ & $0.33 \mathrm{~b}$ & 16.7:1 cde \\
\hline Sweet-sour-2 & $21.0 \mathrm{~b}$ & $21.1 \mathrm{~b}$ & $1.00 \mathrm{a}$ & $5.58 \mathrm{~b}$ & $0.29 \mathrm{c}$ & $19.4: 1 \mathrm{bc}$ \\
\hline Sweet-sour-3 & $20.4 \mathrm{~b}$ & $20.9 \mathrm{~b}$ & $0.98 \mathrm{ab}$ & $5.44 \mathrm{~b}$ & $0.30 \mathrm{bc}$ & $18.1: 1 \mathrm{~cd}$ \\
\hline
\end{tabular}

${ }^{2}$ Mean separation in columns by Tukey's test, $P=0.05$

Table 3. Fruit chemical characteristics of nance selections.

\begin{tabular}{lccccc}
\hline & $\begin{array}{c}\text { Total } \\
\text { soluble } \\
\text { solids } \\
(\%)\end{array}$ & $\begin{array}{c}\text { Juice } \\
\mathrm{pH}\end{array}$ & $\begin{array}{c}\text { Titratable } \\
\text { acidity } \\
(\%)\end{array}$ & TSS:pH & TSS:TA \\
\hline Selection & $12.2 \mathrm{a}^{\mathrm{z}}$ & $3.3 \mathrm{~d}$ & $0.4 \mathrm{e}$ & $3.7: 1 \mathrm{a}$ & $27.2: 1 \mathrm{a}$ \\
Sangunga & $10.3 \mathrm{~b}$ & $2.6 \mathrm{e}$ & $1.4 \mathrm{~b}$ & $4.0: 1 \mathrm{a}$ & $7.3: 1 \mathrm{~cd}$ \\
Conical & $10.6 \mathrm{~b}$ & $3.5 \mathrm{c}$ & $1.4 \mathrm{bc}$ & $3.0: 1 \mathrm{~b}$ & $7.6: 1 \mathrm{~cd}$ \\
Sour-small & $7.6 \mathrm{e}$ & $3.7 \mathrm{~b}$ & $1.0 \mathrm{~d}$ & $2.0: 1 \mathrm{~d}$ & $7.4: 1 \mathrm{~cd}$ \\
Purple & $8.0 \mathrm{de}$ & $3.4 \mathrm{~cd}$ & $1.5 \mathrm{a}$ & $2.3: 1 \mathrm{~cd}$ & $5.3: 1 \mathrm{e}$ \\
Improved & $9.4 \mathrm{c}$ & $3.9 \mathrm{a}$ & $1.4 \mathrm{c}$ & $2.4: 1 \mathrm{c}$ & $6.9: 1 \mathrm{~d}$ \\
Sweet-sour-1 & $9.6 \mathrm{bc}$ & $3.4 \mathrm{~cd}$ & $1.0 \mathrm{~d}$ & $2.4: 1 \mathrm{c}$ & $9.3: 1 \mathrm{~b}$ \\
Sweet-sour-2 & $8.7 \mathrm{~cd}$ & $4.0 \mathrm{a}$ & $1.1 \mathrm{~d}$ & $2.2: 1 \mathrm{~cd}$ & $8.3: 1 \mathrm{bc}$ \\
Sweet-sour-3 & & & & &
\end{tabular}

${ }^{2}$ Mean separation in columns by Tukey's test, $P=0.05$. ratios were calculated from these variables.

Information was analyzed considering each of the 15 chemical and physical determinations as a repetition. CDA was used to take advantage of the relationship between the different variables considered, their multivariate structure and their holistic interaction using the SAS program (SAS Institute, 1995).

\section{Results}

Excluding Purple, which had fruit with purple skin (Fig. 1A), the nance selections had yellow skin (Fig. 1B). Fruit size and taste varied among selections; six of them had fruit of medium (19.3 to $21.1 \mathrm{~mm}$ width) to large (21.5 to $24.8 \mathrm{~mm}$ width) size (Tables 1 and 2). Selections from Mecatán were the only ones that had a sweet-sour flavor.

Mean separation analysis performed on fruit physical and chemical characteristics showed significant differences (Tables 2 and 3 ). Results revealed the influence of the type of parameter used to measure nance fruit quality. However, based on these analyses it was difficult to determine a suitable quality index for nance, therefore, CDA was carried out.

CDA was used to simultaneously evaluate the differences among the six physical and the five chemical variables of the fruit and showed the relative contribution of each variable to the quality of the nance selections. Two CDFs $\left(\mathrm{CDF}_{1}\right.$ and $\left.\mathrm{CDF}_{2}\right)$ explained $>80 \%$ of the accumulated variation among the nance selections (Table 4). Another three CDFs explained $<20 \%$ of the residual variation of fruit characteristics (data not shown).

$\mathrm{CDF}_{1}$ accounted for $55.6 \%$ of the variation among the 11 chemical and physical variables; generating a model composed by those parameters of greater weight giving the model $\mathrm{Y}=2.46 \mathrm{x}_{5}-2.13 \mathrm{x}_{4}+1.42 \mathrm{x}_{3}-3.70 \mathrm{y}_{1}$ $+3.18 \mathrm{y}_{2}+1.03 \mathrm{y}_{5}$ (Table 4). $\mathrm{CDF}_{2}$ accounted for $24.5 \%$ of the variation and was explained by the model $\mathrm{Y}=-2.38 \mathrm{x}_{4}+1.28 \mathrm{x}_{1}+1.16 \mathrm{x}_{3}$ $-7.78 \mathrm{y}_{2}+7.64 \mathrm{y}_{1}$. This analysis found that TSS: TA $\left({ }_{x_{5}}\right)$, TSS:pH $\left({ }_{x_{4}}\right)$, TA $\left({ }_{x_{3}}\right)$, TSS $\left(x_{1}\right)$, both fruit length $\left({ }_{\mathrm{Y}_{1}}\right)$, and width $\left({ }_{\mathrm{Y} 2}\right)$, as well as L: W ratio $\left({ }_{Y 5}\right)$ were the most important canonical coefficients to separate nance selections based on their fruit quality characteristics. However, for the scope of this research, TSS to TA and TSS to $\mathrm{pH}$ ratios were considered the most important chemical indices of fruit quality because a delicate sugar:organic acid ratio provides the typical sweet-sour flavor of nance that is preferred by local customers. TSS by itself should not be the only index for fruit quality because a selection classified as sweet always will have an important proportion of organic acids; furthermore, the $\mathrm{L}$ to $\mathrm{W}$ ratio only defines fruit shape.

The means comparison test of the standardized canonical coefficients (SCCs) for $\mathrm{CDF}_{1}$ showed that the Improved selection was superior to the rest of selections as it had the highest average SCC (Table 5). Fruit of Improved nance had the lowest TSS to TA ratio (5.3:1) and the highest TA content $(1.5 \%)$ indicating an acid or sour taste (Table 3). The Sangunga and Sour-small selections 
Table 4. Standardized canonical coefficients (SCC) and correlation coefficients $(r)$ among canonical discriminant functions $\left(\mathrm{CDF}_{1}, \mathrm{CDF}_{2}\right)$ and fruit quality characteristics of eight nance selections.

\begin{tabular}{|c|c|c|c|c|}
\hline \multirow[b]{2}{*}{ Variable } & \multicolumn{2}{|c|}{$\mathrm{CDF}_{1}$} & \multicolumn{2}{|c|}{$\mathrm{CDF}_{2}$} \\
\hline & $\mathrm{SCC}$ & $r$ & $\mathrm{SCC}$ & $r$ \\
\hline $\mathrm{x}_{1}$. Total soluble solids & 0.70 & 0.36 & 1.28 & -0.51 \\
\hline $\mathrm{x}_{2}$. Juice $\mathrm{pH}$ & -0.86 & -0.08 & -0.58 & 0.61 \\
\hline $\mathrm{x}_{3}^{2}$. Titratable acidity & 1.42 & -0.53 & 1.16 & 0.56 \\
\hline $\mathrm{x}_{4}^{3} \cdot \mathrm{TSS}: \mathrm{pH}$ & -2.13 & 0.14 & -2.38 & -0.74 \\
\hline $\mathrm{x}_{5}^{4} \cdot \mathrm{TSS}: \mathrm{TA}$ & 2.46 & 0.73 & 0.68 & -0.60 \\
\hline $\mathrm{y}_{1}^{3}$. Fruit length & -3.70 & 0.08 & 7.64 & 0.30 \\
\hline $\mathrm{y}_{2}$. Fruit width & 3.18 & 0.41 & -7.78 & 0.14 \\
\hline $\mathrm{y}_{3}$. Fruit fresh weight & -0.14 & 0.40 & 1.61 & 0.30 \\
\hline $\mathrm{y}_{4}$. Seed fresh weight & 0.98 & 0.82 & -0.08 & 0.51 \\
\hline $\mathrm{y}_{5}$. Fruit length:fruit width & 1.03 & -0.68 & -2.76 & 0.34 \\
\hline $\mathrm{y}_{6}$. Percentage of seed weight & & & & \\
\hline in relation to fruit weight & -0.43 & 0.12 & 0.97 & 0.29 \\
\hline Variance explained (\%) & 55.60 & & 24.51 & \\
\hline Eigen value & 2.43 & & 1.06 & \\
\hline
\end{tabular}

had the most negative values of SCCs $(-2.97$ and -2.63 , respectively), which corresponded to the highest TSS to TA ratio, indicating very sweet fruit. A negative correlation $(r=-0.42$; $P>\mathrm{F}=0.0001)$ was found, which meant that TSS increased proportionally as the titratable acidity decreased. Similarly, a negative correlation $(r=-0.33 ; P>\mathrm{F}=0.0001)$ between TSS and juice $\mathrm{pH}$ was found.

The TSS to $\mathrm{pH}$ ratio of Sangunga and Soursmall discriminated the rest of the selections, since they had the highest SCCs values $(-2.97$ and-2.63, respectively) (Table 5), which meant that the sweeter fruit was the result of higher
TSS values (Table 3). However, as it was mentioned before this variable by itself could no be used as a fruit quality index.

Improved selection differed from the rest of selections and had the highest values of length $(24.8 \mathrm{~mm})$ and width $(22.9 \mathrm{~mm})$. In contrast, Sour-small selection had the lowest length and width values, 15.9 and $13.8 \mathrm{~mm}$, respectively. The fruit $\mathrm{L}$ to $\mathrm{W}$ ratio was not an important source of variability to discriminate among selections as it only had a minimum effect in the model for $\mathrm{CDF}_{1}$ and no effect on $\mathrm{CDF}_{2}$.

In the case of $\mathrm{CDF}_{2}, \mathrm{TSS}$ and TA of the juice were the most significant chemical parameters.

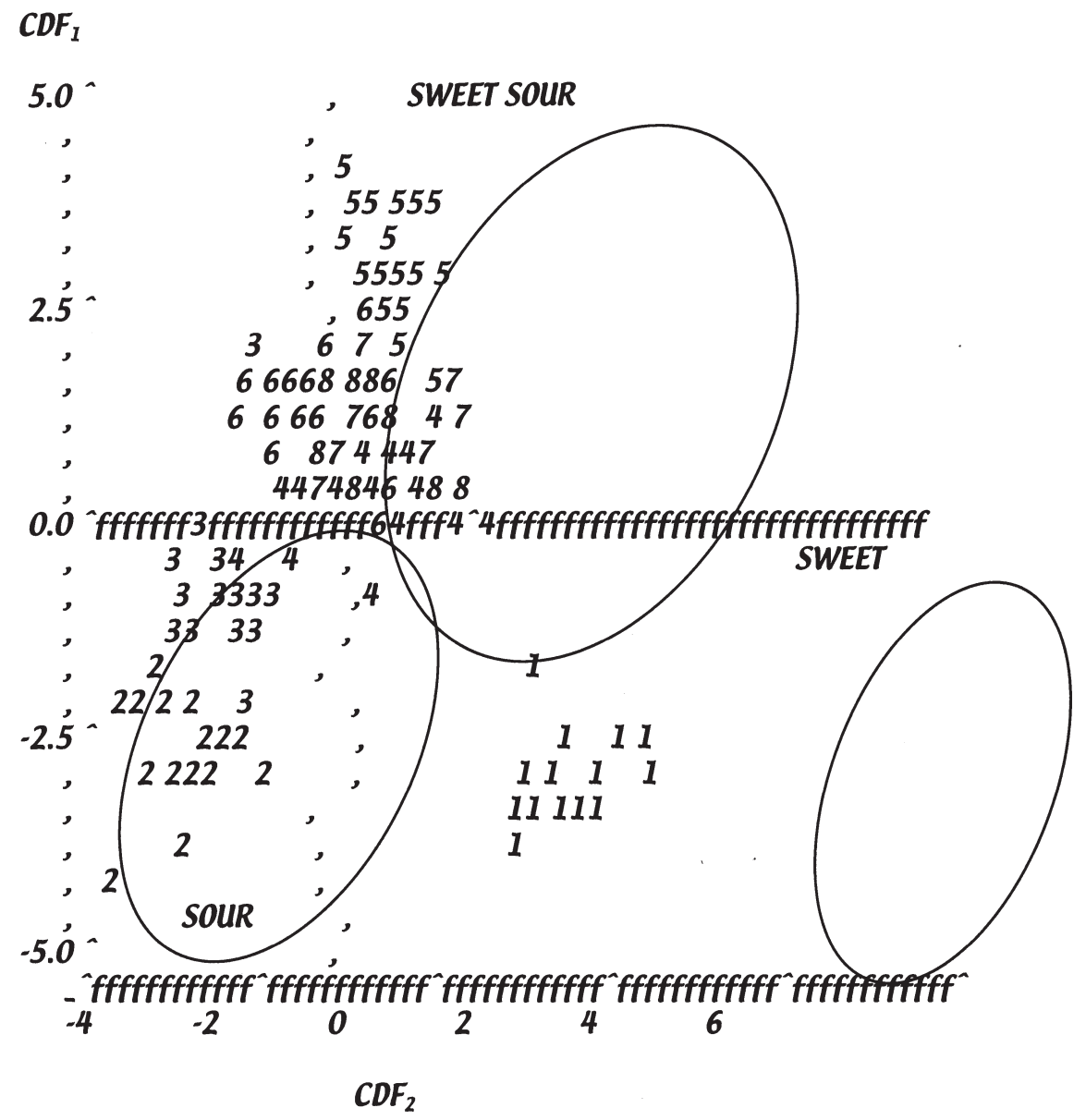

Fig. 2. Canonical coefficients of the canonical discriminant functions $\mathrm{CDF}_{1}$ and $\mathrm{CDF}_{2}$ of eight nance selections. Each number represents a selection: 1) sangunga, 2) sour-small, 3) purple, 4) conical, 5) improved, 6) sweet-sour-1, 7) sweet-sour-2, and 8) sweet-sour-3.
Table 5. Means of standardized canonical coefficients (SCC) of two canonical discriminant functions $\left(\mathrm{CDF}_{1}, \mathrm{CDF}_{2}\right)$ for fruit characteristics in eight nance selections.

\begin{tabular}{lcc}
\hline & \multicolumn{2}{c}{$\begin{array}{c}\text { Standardized canonical } \\
\text { coefficients }\end{array}$} \\
\cline { 2 - 3 } Selection & $\mathrm{CDF}_{1}$ & $\mathrm{CDF}_{2}$ \\
\hline Sangunga & $-2.97 \mathrm{e}^{\mathrm{z}}$ & $3.69 \mathrm{a}$ \\
Conical & $0.29 \mathrm{c}$ & $-0.06 \mathrm{~cd}$ \\
Sour-small & $-2.63 \mathrm{e}$ & $-2.55 \mathrm{f}$ \\
Purple & $-0.77 \mathrm{~d}$ & $-1.97 \mathrm{e}$ \\
Improved & $3.20 \mathrm{a}$ & $-0.95 \mathrm{~b}$ \\
Sweet-sour-1 & $1.22 \mathrm{~b}$ & $-0.53 \mathrm{~d}$ \\
Sweet-sour-2 & $0.96 \mathrm{~b}$ & $0.31 \mathrm{c}$ \\
Sweet-sour-3 & $0.98 \mathrm{~b}$ & $-0.02 \mathrm{~cd}$ \\
\hline${ }^{2}$ Mean separation in columns by Tukey's test, $P$ \\
$=0.05$.
\end{tabular}

Sangunga differed from the rest of selections in the TSS to TA ratio (27.2:1) (Table 3). The TSS to $\mathrm{pH}$ ratio had the highest SCC $(-2.38)$ among the chemical parameters (Table 4 ) and was the most useful for discriminating among the nance selections with regard to this characteristic (Table 3). Juice $\mathrm{pH}$ alone was not useful for either $\mathrm{CDF}_{1}$ or $\mathrm{CDF}_{2}$.

From the fruit physical variables examined by $\mathrm{CDF}_{2}$ and $\mathrm{CDF}_{1}$, fruit length and width were more important than fruit or seed weight for discriminating among selections. The fresh fruit weight of the Improved selection (8.87 $\mathrm{g} /$ fruit) was significantly heavier than the rest of selections and had the highest SCC value (1.61) (Table 4). Tukey's test applied to the SCCs of $\mathrm{CDF}_{1}$ and $\mathrm{CDF}_{2}$ allowed plotting of the different nance groups based on their fruit physical and chemical characteristics (Fig. 2). Three groups were clearly distinguished: a) sweet (Sangunga), b) sour (Sour-small and purple), and c) sweet-sour (Conical, Improved, Sweet-sour-1, Sweet-sour-2 and Sweet-sour-3).

\section{Discussion}

CDA was used to simultaneously relate fruit chemical and physical characteristics of seven yellow and one purple nance selections and determine a quality index. Regarding physical characteristics, the most significant parameters for discriminating among the selections were fruit length and width as well as its ratio (L to $\mathrm{W})$. However, these parameters may only define a customer's preference for a certain fruit size and/or shape.

From the chemical characteristics studied, titratable acidity appeared to be a good parameter to assess fruit quality. However, Blanpied and Black (1977) and Lau (1985) pointed out that this parameter could change after harvest. The possibility that these changes occur in nance fruit deserves further evaluation.

Juice titratable acidity, $\mathrm{pH}$, and total soluble solids were the most important parameters to define the quality of nance fruit as similarly concluded for pear fruit Vangdal (1982) and Wang (1982). In nance, like with other fruit (Wills et al., 1980), fruit quality could be determined with the TSS to TA ratio. This ratio was the dominant parameter in $\mathrm{CDF}_{1}(\mathrm{SCC}=$ 2.46); hence, this ratio was chosen as the best chemical index to establish differences among 
nance selections, since individual values of TSS and TA could not be appropriate because local customers prefer sweet-sour nance fruit. The following TSS to TA ratios are proposed to classify nance fruit: a) 5.1 to 8 as sour fruit (Sour-small and Purple selections), b) 8.1 to 10 as sweet-sour fruit (Conical, Improved, Sweet-sour-1, Sweet-sour-2 and Sweet-sour-3 selections), and c) $>10$ as sweet fruit (Sangunga selection).

The CDA was a useful tool to determine the best nance fruit quality based on physical and/or chemical parameters. This shown by the fact that $\mathrm{CDF}_{1}$ and $\mathrm{CDF}_{2}$ explained $>80 \%$ of the accumulated variation among the eight nance selections included in this study. The information from this research could be used as a criterion to select nance trees with uniform fruit quality for either direct consumption or processing.

\section{Literature Cited}

Blanpied, G.D. and V.A. Black. 1987. A comparison of pressure tests, acid levels and sensory evaluation of overripeness in apples. HortScience 12:73-74.

Cruz-Castillo, J.C., S. Ganeshanandam, B.R. McKay, G.S. Lawes, C.R.O. Lawoko, and D.J. Woolley. 1994. Applications of canonical discriminant analysis in horticultural research. HortScience 29:1115-1119.

Herrero, A. and J. Guardia. 1992. Conservación de frutos. Manual técnico. Ed. Mundi-Prensa. Madrid, España.

Kshirsagar,A.M. 1972. Multivariate analysis. Marcel Dekker, New York.

Lau, O.L. 1985. Harvest indices for apples. B.C. Orchardist 7(7):1-20.

Mann, S.S. and B. Singh. 1985. Some aspects of developmental physiology of 'LeConte' pear. Acta Hort. 158:211-215.

Nava K., G.G. and Uscanga, M.B. 1978. Contribución al estudio de nueve tipos de Spondias sp. y 17 tipos de Byrsonima crassifolia L. en dos regiones del estado de Veracruz, p. 819-834. In: CONAFRUT.
Memoria del Simposium La investigación, el desarrollo experimental y la docencia. Comisión Nacional de Fruticultura, México.

Pennington, D.T. and K.J. Sarukhan. 1968. Manual para la identificación de campo de los principales árboles tropicales de México. Instituto Nacional de Investigaciones Forestales-ONU, México. 1ra. Ed. p. 248-249.

Rencher, A.C. 1992. Interpretation of canonical discriminant functions, canonical variates, and principal components. Amer. Stat. 46:217-225.

SAS Institute Inc. 1995. SAS Procedures guide. version $6.7^{\text {th }}$ ed. vol. 1. SAS Inst., Cary, N.C.

Vangdal, E. 1982. Eating quality of pears. Acta Agr. Scand. 33:135-139.

Wang, C.Y. 1982. Pear fruit maturity, harvesting, storage and ripening, p. 431-443. In: T. van der Zwet and N.F. Childers (eds.). The pear. Horticultural Publishers. Gainesville, Fla.

Wills, R.B.H., P.A. Bambridge, and K.J. Scott. 1980. The use of the flesh firmness and other objective tests to determine consumer acceptability of 'Delicious' apples. Austral. J. Expt. Agr. Animal Husb. 20:252-256. 